\title{
FSH directly regulates chondrocyte dedifferentiation and cartilage development
}

\author{
Yan Wang 1,2,3,4, Mengqi Zhang 1,2,3,4, Zhikun Huan',2,3,4, Shanshan Shao 1,2,3,4, Xiujuan Zhang 1,2,3,4, Dehuan Kong5 and \\ Jin $\mathrm{Xu}^{1,2,3,4}$ \\ 'Department of Endocrinology, Shandong Provincial Hospital, Cheeloo College of Medicine, Shandong University, Jinan, Shandong Province, China \\ 2Shandong Provincial Key Laboratory of Endocrinology and Lipid Metabolism, Jinan, Shandong Province, China \\ ${ }^{3}$ Cheeloo College of Medicine, Shandong University, Jinan, Shandong Province, China \\ 4Department of Endocrinology, Shandong Provincial Hospital Affiliated to Shandong First Medical University, Jinan, Shandong Province, China \\ ${ }^{5}$ Department of Endocrinology, Taian City Central Hospital, Taian, Shandong Province, China
}

Correspondence should be addressed to J Xu: xujin267903@163.com

\begin{abstract}
Previous studies suggest that postmenopausal osteoarthritis is linked to a decrease in estrogen levels. However, whether follicle-stimulating hormone (FSH), the upstream hormone of estrogen, affects cartilage destruction and thus contributes to the onset of osteoarthritis has never been explored. To evaluate the potential involvement of FSH in joint degeneration and to identify the molecular mechanisms through which FSH influences chondrocytes, mouse cartilage chondrocytes and the ATDC5 chondrocyte cell line were treated with FSH and inhibitors of intracellular signaling pathways. We observed that FSH induces chondrocyte dedifferentiation by decreasing type II collagen (Coll-II) synthesis. Chondrocyte cytoskeleton reorganization was also observed after FSH treatment. The FSH-induced decrease in Coll-II was rescued by ERK-1/2 inhibition but aggravated by p38 inhibition. In addition, knocking down the FSH receptor (Fshr) by using Fshr siRNA abolished chondrocyte dedifferentiation, as indicated by the increased expression of Coll-II. Inhibition of the protein Gai by pertussis toxin (PTX) also restored FSH-inhibited Coll-Il, suggesting that Goi is downstream of FSHR in chondrocyte dedifferentiation. $\mathrm{FSH} \beta$ antibody blockade prevented cartilage destruction and cell loss in mice. Moreover, decreased Coll-Il staining due to the progression of aging could be rescued by blocking FSH. Thus, we suggest that high circulating FSH, independent of estrogen, is an important regulator in chondrocyte dedifferentiation and cartilage destruction.
\end{abstract}

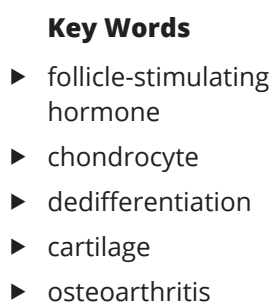

Journal of Endocrinology (2021) 248, 193-206

\section{Introduction}

Osteoarthritis (OA) is a degenerative disease affecting more than $70 \%$ of the population ranging from 55 to 77 years of age (Johnson et al. 2012). Many risk factors, such as age, sex, obesity, injury, and mechanical factors, are involved in the progression of OA. Some studies have shown that the incidence of $\mathrm{OA}$ is higher in females than in males, especially after menopause (Zhang \&
Jordan 2010, Hunter \& Bierma-Zeinstra 2019). Until recently, the underlying mechanisms of OA have been linked to the decrease in estrogen that occurs with the onset of menopause (Martin-Millan \& Castaneda 2013). Although FSH levels increase in parallel, the effect of FSH on cartilage and chondrocytes has never been explored. 
FSH is a glycoprotein synthesized by the pituitary and is controlled by estrogenic feedback. FSH acts by binding its receptor FSH receptor (FSHR). Extragonadal FSHRs are expressed in a variety of cells, such as hepatocytes (Guo et al. 2019), adipocytes (Cui et al. 2012, Liu et al. 2015, 2017), and osteoclasts (Sun et al. 2006). Based on our previous study, FSHR is expressed on human and mouse chondrocytes (Kong et al. 2018). We speculate that FSH may exert effects on chondrocytes, consequently affecting osteoarthritis development.

Although OA is considered a disease that involves the whole joint, the articular cartilage is altered to some extent in affected joints with OA. Articular cartilage is an avascular organ consisting of distributed chondrocytes surrounded by an extracellular framework. Chondrocytes are the only cellular component of articular cartilage, and they can secrete extracellular matrix (ECM) components, such as type 2 collagen (Coll-II) and aggrecan (Poole 1997). Chondrocytes also produce catabolic molecules such as matrix metalloproteinases (MMPs) involved in the degradation of the ECM (van der Kraan \& van den Berg 2012). In healthy cartilage, chondrocytes regulate cartilage homeostasis by maintaining a very low turnover ECM rate and balancing anabolism and catabolism. Chondrocytes acquire OA-associated phenotypes by changing their behavior. It is well documented that chondrocytes undergo mature hypertrophic differentiation and exhibited enhanced catabolism during the process of OA (Rim et al. 2020). However, recent studies have shown that chondrocytes can acquire other degenerative phenotypes (i.e. prehypertrophic, dedifferentiation) (Charlier et al. 2019, Li et al. 2019a, Speichert et al. 2019). It is therefore important to understand chondrocyte behavior in response to FSH in OA pathogenesis.

In the present study, we explored the effects and mechanisms of FSH on cartilage chondrocytes by using in vitro and in vivo studies. Mouse primary chondrocytes and the ATDC5 cell line were used to investigate whether FSH activation could disrupt ECM homeostasis and affect chondrocyte dedifferentiation. In addition, the possible signaling mechanisms underlying FSH-altered dedifferentiation were also evaluated. We also evaluated the effect of FSH absence on cartilage in vivo using FSH $\beta$ antibody blockade. To our knowledge, this is the first study to demonstrate that FSH has a direct effect on chondrocyte dedifferentiation. Blocking FSH might be an option to treat joint disorders, such as postmenopausal osteoarthritis.

\section{Experimental procedures}

\section{Animals}

C57BL/6J mice were purchased from Vital River Laboratory Animal Technology Co., Ltd. (Beijing, China). Mice were housed at room temperature $\left(25^{\circ} \mathrm{C}\right)$ under a $12 \mathrm{~h}$ light: 12 $\mathrm{h}$ darkness cycle. Mice were intraperitoneal injected anti-FSH $\beta$ antibody (Medix Mab, \#6602, BiosPacific, Emeryville, CA) or anti-IgG antibody (Proteintech, Wuhan, China) at $100 \mu \mathrm{g} /$ day daily for 8 weeks (Guo et al. 2019). All animal protocols were conducted with the approval of the Animal Study Committee of Shandong Provincial Hospital.

\section{Isolation and culture of primary chondrocytes}

The direct effects of FSH on cartilage were assessed using primary chondrocytes. Primary chondrocytes were isolated from the distal femoral and proximal tibia of newborn mice (C57BL/6J) as described previously (Gosset et al. 2008). After careful dissection of adherent tissue, the cartilage was cut into $1 \mathrm{~mm}^{2}$ pieces and digested in full culture medium containing $1 \mathrm{mg} / \mathrm{mL}$ collagenase $\mathrm{P}$ (Roche) and $0.145 \mathrm{mM}$ L-cysteine. Then, chondrocytes were seeded and cultured in DMEM/F12 (HyClone, GE Healthcare) containing 10\% FBS (Bio-Excel, New Zealand, Australia), $100 \mathrm{U} / \mathrm{mL}$ penicillin, $100 \mu \mathrm{g} / \mathrm{mL}$ streptomycin (Gibco), $44 \mu \mathrm{g} / \mathrm{mL}$ ascorbic acid (Solarbio, Beijing, China) and $130 \mu \mathrm{g} / \mathrm{mL}$ ascorbic acid-2-phosphate (Sigma-Aldrich), at $37^{\circ} \mathrm{C}$ in a humid environment with $5 \% \mathrm{CO}_{2}$ (Xin et al. 2015). Primary chondrocytes were never passaged and were cultured for no more than 1 week. The cells isolated were identified by the expression of type II collagen (data not shown). Before treatment with FSH (R\&D, \#8576-FS), chondrocytes were starved $2 \mathrm{~h}$ before the experiment. Primary chondrocytes were treated with recombinant mouse FSH or vehicle. For MAPK signal analysis, PD98059 ERK inhibitor and SB203580 p38 inhibitor were purchased from Beyotime Biotechnology (Nanjing, China).

\section{ATDC5 cell line culture}

The mouse chondrogenic cell line ATDC5 was purchased from Wuhan Procell Life Science \& Technology Co., Ltd. Cells were cultured in a 1:1 mixture of DMEM and DME/ F12 medium containing $5 \%$ FBS at $37^{\circ} \mathrm{C}$ under $5 \% \mathrm{CO}_{2}$. Differentiation was induced by the addition of $10 \mu \mathrm{g} / \mathrm{mL}$ insulin, $5.5 \mu \mathrm{g} / \mathrm{mL}$ transferrin, and $5 \mu \mathrm{g} / \mathrm{mL}$ sodium selenite (ITS; Sigma) with $250 \mu \mathrm{m}$ ascorbate for 2 weeks. 


\section{CCK-8 assay}

The CCK-8 assay was used to assess whether FSH can affect chondrocyte apoptosis or proliferation. Briefly, mouse primary chondrocytes were seeded into a 96-well plate at a density of $4 \times 10^{3} /$ well. Then $10 \mu \mathrm{L}$ of the CCK- 8 solution (Dojindo Laboratories, Kumanmoto, Japan) was added to each well. The cell viability was then detected at different time points $(24,48$, and $72 \mathrm{~h})$ at $450 \mathrm{~nm}$ using a microplate reader.

\section{Immunoblotting}

Cell culture supernatants were discarded and then washed with PBS. Then, the cell layer was scraped and lysed with RIPA and PMSF on ice. Total protein was loaded on 8-10\% SDS-PAGE gels and transferred onto PVDF membranes (0.45 $\mu \mathrm{m}$, Millipore) and blocked with 5\% non-fat milk. After incubated with primary antibodies against type II collagen (Abcam), SOX9 (Abcam, \#ab185966), total ERK (CST, \#4695), p-ERK (CST, \#4370), total p38 (CST, \#8690), p-p38 (CST, \#4511), total CREB (CST, \#9197), p-CREB (CST, \#9198s), FSHR (Proteintech, \#22665-1-AP) and GAPDH (Absin, \#abs137959), the membranes were incubated with an HRP-conjugated secondary antibody. Protein bands were detected using an ECL detection kit (Millipore). GAPDH or ERK-1/2 was used as a control.

\section{RNA extraction and qRT-PCR}

Total RNA was extracted using TRIzol reagent (Takara) and reverse transcribed into cDNA using a Takara kit. The concentration of total RNA was measured by a NanoDrop1000 (NanoDrop, USA). Gene expression was quantified by real-time PCR in a Roche 480 Real-Time PCR system. The PCR primer sequences were as reported previously (Table 1).

\section{Analysis of intracellular CAMP}

For the analysis of adenosine 3',5'-cyclic monophosphate (cAMP) content, primary chondrocytes were incubated with forskolin (Forsk) as a positive control to stimulate cAMP production. Since Goi protein is sensitive to pertussis toxin (PTX), chondrocytes were pretreated with PTX at a concentration of $100 \mathrm{ng} / \mathrm{mL}$ for $12 \mathrm{~h}$ before FSH treatment. After treatment with FSH for $30 \mathrm{~min}$, cell lysates were collected and measured using an ELISA kit (Cayman, \#581001) according to the manufacturer's instructions. (c) 2021 Society for Endocrinology Published by Bioscientifica Ltd.
Printed in Great Britain
Table 1 RNA primers.

\begin{tabular}{|c|c|}
\hline Gene name & Forward and reverse primer $\left(5^{\prime}-3^{\prime}\right)$ \\
\hline Col2a1 & $\begin{array}{l}\text { F: CACACTGGTAAGTGGGGCAAGACCG } \\
\text { R: GGATTGTGTTGTTTCAGGGTTCGGG }\end{array}$ \\
\hline Acan & $\begin{array}{l}\text { F: CTGTCTTTGTCACCCACACA TG } \\
\text { R: GAAGACGACATCACCA TCCAG }\end{array}$ \\
\hline Sox9 & $\begin{array}{l}\text { F: ATCTCCCACCCAGAACCTCT } \\
\text { R: CAGGGCAGGAGAGTTGAGAC }\end{array}$ \\
\hline Sox 5 & $\begin{array}{l}\text { F: TGGCAATGGGATCAGGGAAC } \\
\text { R: ATCATACCCATGAGCTGCCG }\end{array}$ \\
\hline Sox6 & $\begin{array}{l}\text { F: ATCTCCCACCCAGAACCTCT } \\
\text { R: CAGGGCAGGAGAGTTGAGAC }\end{array}$ \\
\hline Mmp3 & $\begin{array}{l}\text { F: AGGGATGATGATGCTGGTATGG } \\
\text { R: CCA TGTTCTCCAACTGCAAAGG }\end{array}$ \\
\hline Mmp13 & $\begin{array}{l}\text { F: GGAGTTTACAGGAAGCAGACA } \\
\text { R: CATCCACA TGGTTGGGAAGTTCT }\end{array}$ \\
\hline Col10a1 & $\begin{array}{l}\text { F: CTTTGTGTGCCTTTCAATCG } \\
\text { R: GTGAGGTACAGCCTACCAGTTTT }\end{array}$ \\
\hline Prg4 & $\begin{array}{l}\text { F: GACGCCCAATGTAAGAAG } \\
\text { R: GCAAGGGTGAGACAAGAA }\end{array}$ \\
\hline Egr1 & $\begin{array}{l}\text { F: TCGGCTCCTTTCCTCACTCA } \\
\text { R: CTCATAGGGTTGTTCGCTCGG }\end{array}$ \\
\hline Pthlh & $\begin{array}{l}\text { F: CATCAGCTACTGCATGACAAGG } \\
\text { R: CTGTGTGGATCTCCGCGAT }\end{array}$ \\
\hline Ihh & $\begin{array}{l}\text { F: GGCGCTACGAAGGCAAGAT } \\
\text { R: CTTGAAGATGATGTCGGGATTGT }\end{array}$ \\
\hline Fshr & $\begin{array}{l}\text { F: CCTTGCTCCTGGTCTCCTTG } \\
\text { R: CTCGGTCACCTTGCTATCTTG }\end{array}$ \\
\hline Gapdh & $\begin{array}{l}\text { F: TCACTGCCACCCAGAAGAC } \\
\text { R: TGTAGGCCATGAGGTCCAC }\end{array}$ \\
\hline
\end{tabular}

Immunofluorescence

Chondrocytes were fixed with $4 \%$ paraformaldehyde and permeabilized with $0.5 \%$ Triton X-100 for $30 \mathrm{~min}$. In total, 5\% BSA was used as a blocking solution. Rabbit polyclonal anti-FSHR antibody (Proteintech, \#22665-1-AP) was added to the cells overnight at $4^{\circ} \mathrm{C}$ followed by staining with Cy3-conjugated anti-rabbit antibody in the dark. For actin cytoskeleton analysis, ATDC5 cells were stained with Rhodamine phalloidin (Cytoskeleton, \#PHDR1) for $30 \mathrm{~min}$ at $37^{\circ} \mathrm{C}$. For Egr1 staining, rabbit polyclonal anti-Egr1 antibody (Proteintech, \#22008-1-AP) was added and incubated overnight at $4^{\circ} \mathrm{C}$. Alexa Fluor Plus 488 anti-rabbit antibody (Invitrogen, \#A32731) was used as the secondary antibody. Nuclei were counterstained with DAPI (Abcam) for $5 \mathrm{~min}$. The cells were visualized with darkfield microscopy (LSM 780, Zeiss).

\section{Transfection of siRNA}

Three pairs of siRNA (siRNA) (\#1, \#2, \# 3) (Table 2) specific for FSHR and a scrambled control were synthesized by Genomeditech Co., Ltd. (Shanghai, China). The siRNA sequences specific for FSHR were selected based on their potency to inhibit more than $80 \%$ fshr expression. 
Table 2 Sequences of Fshr siRNA.

\begin{tabular}{|c|c|}
\hline Fshr siRNA & Forward and reverse primer $\left(5--3^{\prime}\right)$ \\
\hline \#1 & $\begin{array}{l}\text { F: UAGAAAGAUGGCAUACCAU tt } \\
\text { R: AUGGUAUGCCAUCUUUCUA tt }\end{array}$ \\
\hline \#2 & $\begin{array}{l}\mathrm{F}: \text { GUCUCCGAUAUCUGUUAAU tt } \\
\text { R: AUUAACAGAUAUCGGAGAC tt }\end{array}$ \\
\hline \#3 & $\begin{array}{l}\text { F: GAGUCUUGAUAUGGUUUAU tt } \\
\text { R: AUAAACCAUAUCAAGACUC } t t\end{array}$ \\
\hline
\end{tabular}

The transfection of $100 \mathrm{nM}$ fshr-siRNA was performed using Lipo3000 transfection reagent (Invitrogen) according to the manufacturer's instructions.

\section{Histology}

Knee joint tissue samples were fixed in 4\% paraformaldehyde overnight and decalcified at $0.5 \mathrm{M}$ EDTA (Servicebio, China) for 3 weeks. After decalcification, the mouse knee joints were dehydrated and embedded in paraffin. Five- $\mu \mathrm{m}$ serial sagittal sections were cut from the lateral tibiofemoral joint ( 100 sections were cut). Then sections corresponding to $1 / 4$ (sections $\sim 25$ ), $2 / 4$ (sections $\sim 50$ ), $3 / 4$ (sections $\sim 75$ ) and $4 / 4$ (sections $\sim 100$ ) of the joint were selected to evaluate the whole cartilage. For comparison, the sections were selected from the same location. Safranin O/Fast Green was stained to observe the cartilage. Histological data were analyzed by assessing the Mankin score (Mankin et al. 1971, Aigner et al. 2010) and OARSI score (Pritzker et al. 2006). The scoring of the sections was performed by two experienced observers in a blinded manner.

\section{Immunohistochemistry and Alcian blue staining}

Mouse cartilage sections were stained to assess FSHR location. Briefly, sections were deparaffinized, rehydrated, and immunostained according to the manufacturer's instructions. The sections were incubated with FSHR (Proteintech, \#22665-1-AP), type II collagen, Ki67 (Abcam, \#ab15580), and Egr1 (Proteintech, \#22008-1-AP) antibody at $37^{\circ} \mathrm{C}$ for $1 \mathrm{~h}$. The sections were counterstained with toluidine blue to verify cartilage. The slides were visualized under a light microscope (Leica).

ATDC5 cells were fixed in 4\% paraformaldehyde for 15 min at room temperature and then stained with Alcian blue (Sigma-Aldrich) overnight. Then, the cells were washed with PBS and $0.1 \mathrm{M} \mathrm{HCl}$ to remove the background.

\section{Statistical analysis}

All experiments were performed at least three times. Data are expressed as the mean \pm s.E.M. and were analyzed using GraphPad Prism software version 6.0 (GraphPad Software, Inc.). Non-parametric test followed by Mann-Whitney test was used for the comparison of two groups and non-parametric test followed by Kruskal-Wallis test was used for the comparison of multiple groups. $P$-values less than 0.05 were considered statistically significant.

\section{Results}

\section{FSHR activation leads to decreased Coll-II synthesis}

FSH is the pituitary hormone responsible for the stimulation of estrogen, and it is increased after menopause. Although the receptor of FSH, FSHR, is expressed on chondrocytes (Kong et al. 2018), whether FSH plays role in cartilage homeostasis has never been investigated. To examine FSH affected cell viability, the CCK-8 assay was performed. No significant changes in cell viability were observed after FSH treatment. The in vitro results indicate that FSH has no cytotoxicity and does not affect cell apoptosis (Fig. 1A).

Given that ECM shifts during changes in chondrocyte behavior and during the progression of OA, we performed real-time quantitative RT PCR (qRTPCR) and immunoblotting to evaluate the effects of FSH on primary chondrocytes. mRNA analyses demonstrated that the expression of genes related to ECM synthesis (Sox9, Sox5, Sox6, Col2a1, Acan) and chondrocyte hypertrophic differentiation (Col10a1, Mmp3, Mmp13) were decreased after FSH treatment (Fig. 1B). This is consistent with former studies that the general DNA methylation level is increased during dedifferentiation, leading to a decrease of gene expression (Ma et al. 2013, Duan et al. 2017). Chondrocyte differentiation is regulated by the PTHrP-Indian hedgehog (Ihh) negative feedback loop. PTHrP (also known as Pthlh) acts downstream of Ihh to inhibit chondrocyte hypertrophic differentiation (Kobayashi et al. 2002). In our present study, Pthlh was sharply increased and $I h h$ was decreased (Fig. 1A), suggesting that the hypertrophic differentiation is inhibited.

Moreover, immunoblotting analysis showed that Coll-II, the main collagen in cartilage and a differentiation marker, was reduced in a dose-dependent manner after FSH treatment (Fig. 1C), indicating a trend toward chondrocyte dedifferentiation. The chondrogenic transcription factor SRY-type high-mobility-group box (SOX9) was also reduced in a dose-dependent manner (Fig. 1C). A previous study suggested that the 
A

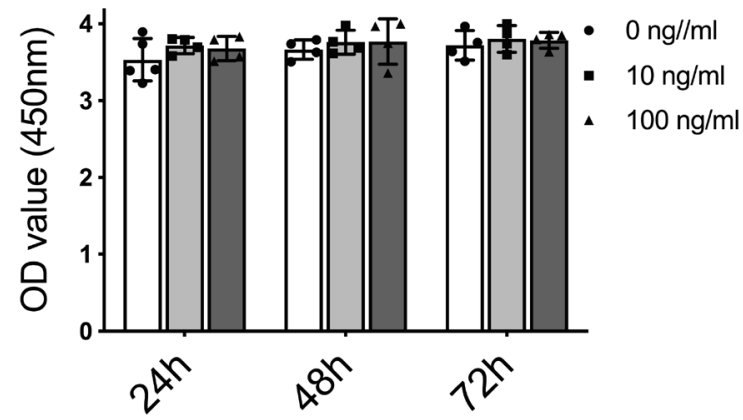

$\mathrm{B}$

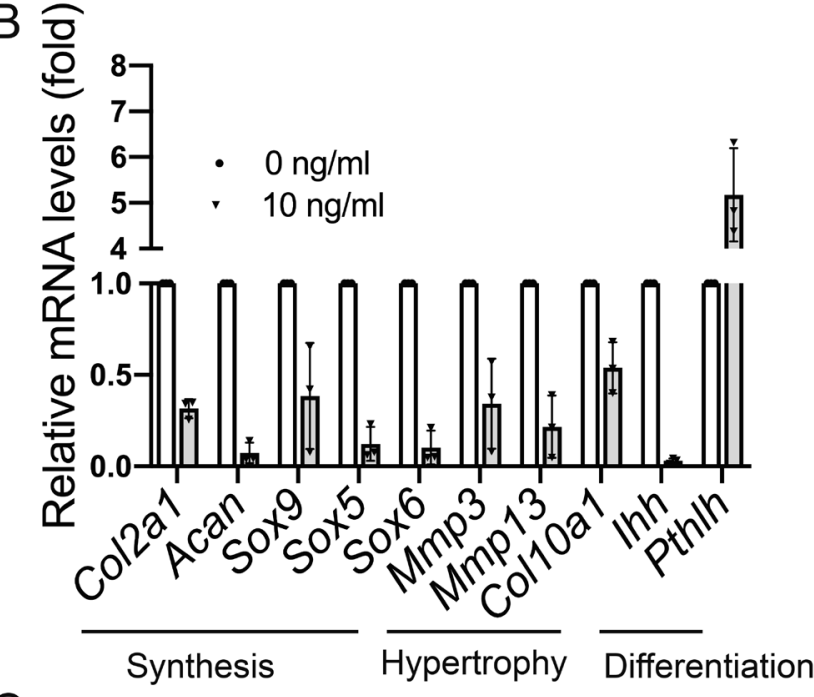

C

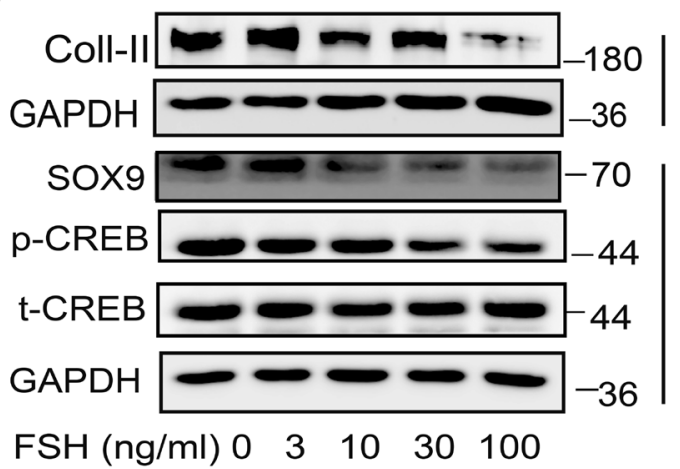

Figure 1

FSH reduces ECM synthesis and promotes cell dedifferentiation in primary chondrocytes. (A) FSH did not affect chondrocyte viability at 24,48 and 72 $\mathrm{h}$ by the CCK-8 assay. (B) The effect of FSH $(10 \mathrm{ng} / \mathrm{mL})$ on genes related to ECM synthesis, chondrocyte hypertrophy and differentiation, $* P<0.05$ vs control. (C) Effect of different doses of FSH on Coll-II, SOX9, total-CREB (t-CREB) and phospho-CREB ( $p$-CREB). GAPDH was used as a control.

cAMP-response element-binding protein (CREB) CBP/ p300 interacts with SOX9 to enhance Coll-II transcription (Tsuda et al. 2003). Therefore, we also analyzed the phosphorylation level of CREB and observed a dose-dependent decrease after FSH treatment (Fig. 1C).
The decreases in Coll-II was in parallel with decreases in SOX9 and p-CREB (Fig. 1C).

\section{FSH activation induces actin cytoskeleton reorganization}

Chondrocytes change to a round and large phenotype during hypertrophic differentiation, while they change to a fibroblast phenotype during dedifferentiation (Charlier et al. 2019). Therefore, we performed an immunofluorescence assay to analyze the effect of FSH on the cell cytoskeleton.

The ATDC5 cell line is a well-validated chondrogenic cell line in chondrocyte differentiation. We stained ATDC5 cells with a FSHR antibody and confirmed that the FSH receptor is located on the surface of ATDC5 cells (Fig. 2A). Then, we treated ATDC5 cells with FSH, showing that FSH markedly alters the actin cytoskeletal architecture by changing ATDC5 cells to a fibroblastlike cell phenotype, as evidenced by phalloidin staining (Fig. 2B). These data support that FSH induces chondrocyte cytoskeleton reorganization, which is a sign of chondrocyte dedifferentiation.

\section{FSH modulates Coll-II by binding to FSHR}

To examine whether FSH-modulated chondrocyte dedifferentiation was mediated by FSHR, we knocked down Fshr in primary chondrocytes by using Fshr siRNA. The efficiency of Fshr siRNA to knockdown FSHR was detected by qRT-PCR (Fig. 3A) and western blot (Fig. 3B). And the results showed that only the second pair of siRNA (\#2) has the highest efficiency to knockdown Fshr, so we use pair \#2 in the following study. Interfering with Fshr siRNA upregulates Coll-II (Fig. 3C), suggesting that FSH regulates Coll-II by binding its receptor FSHR. In the present study, even though we interfered with Fshr by using Fshr siRNA, we still observed a nonsignificant decrease in Coll-II after FSH treatment in the Fshr siRNA group (Fig. 3C). A plausible explanation for this may be that FSH stimulation upregulates the expression of FSHR (Cui et al. 2012). To explore FSHRmediated signaling pathways, we measured the levels of the second messenger cyclic AMP (cAMP) by using an ELISA kit after FSH treatment. Forskolin is known to increase cAMP levels, so we used it as a positive control. The results showed that FSH inhibits cAMP production in primary chondrocytes. The reduced cAMP can be restored by pertussis toxin (PTX), a Goi inhibitor 
A

ATDC5

10

30

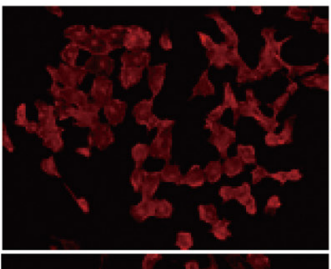

$\mathrm{FSH}$

$(\mathrm{ng} / \mathrm{ml})$
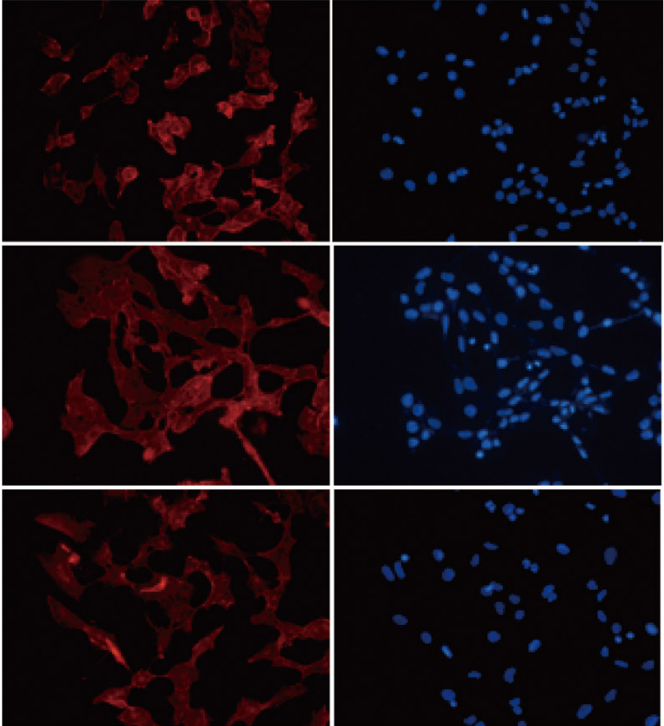

Pholloidine

DAPI

(Fig. 3D), suggesting that FSH may functions by binding to its Gai coupled FSHR.

\section{ERK-1/2 and p38 kinase pathways are involved in FSH-mediated dedifferentiation}

ERK and p38 kinase pathways have been confirmed to be involved in chondrogenesis and chondrocyte dedifferentiation (Kim et al. 2002, Yu \& Kim 2015, Yu et al. 2016a,b). Thus, we measured whether the coupling of FSHR could alter ERK-1/2 and p38 activities. Western blot analysis results showed that FSH stimulates ERK-1/2 phosphorylation but inhibits p38 phosphorylation within $30 \mathrm{~min}$ in a dose-dependent manner (Fig. 4A). We next examined the roles of ERK-1/2 and p38 signaling in FSH-mediated pathways by using signaling inhibitors. Inhibition of the ERK-1/2 and p38 pathways was achieved with the ERK inhibitor PD98059 (PD) and p38 inhibitor

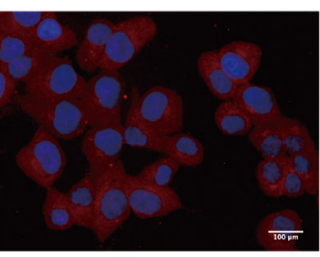

Merge

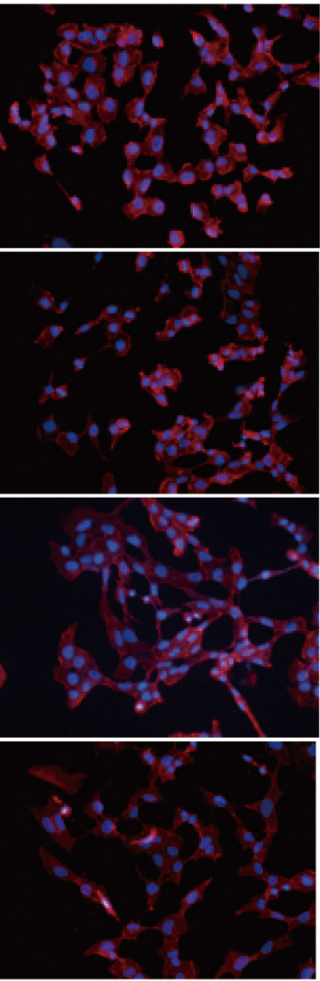

Merge $\quad 2 \overline{200} \mathrm{~m}$

\section{Figure 2}

FSH activation induces actin cytoskeleton reorganization in ATDC5 cells. (A) FSHR localization was visualized by

immunofluorescence in ATDC5 cells. The cell nucleus was defined by DAPI (blue). Darkfield microscope was obtained from Zeiss (Axio Image A2, Germany). Scale bars $=100 \mu \mathrm{m}$. (B) The cytoskeleton of ATDC5 cells was stained with Rhodamine phalloidin (red) after FSH treatment for $30 \mathrm{~min}$, and the nucleus was stained with DAPI (blue). Scale bars $=200 \mu \mathrm{m}$.
SB203580 (SB). As revealed by Western blotting results, the FSH-mediated inhibition of Coll-II was rescued by PD but aggravated by SB (Fig. 4B). Proteoglycans are indicators of chondrocyte differentiation, which can be detected by Alcian blue staining. The results showed that the proteoglycan accumulation was slightly inhibited after FSH treatment. However, the decrease in proteoglycan could be restored by $\mathrm{PD}$ but aggravated by SB (Fig. 4C). These data suggest that ERK-1/2 and p38 play critical roles in FSH-mediated chondrocyte dedifferentiation.

It is well established that Goi is one of the most potent $G$ proteins that regulates the MAPK signaling pathway (Leroy et al. 2007, Li et al. 2019b). The pretreatment with PTX restores FSH increased p-ERK-1/2 (Fig. 4D), indicating that the change in ERK-1/2 in response to FSH is sensitive to Goi. In line with this, PTX restores FSH downregulated Coll-II (Fig. 4D), suggesting that Goi involves in FSH 
A

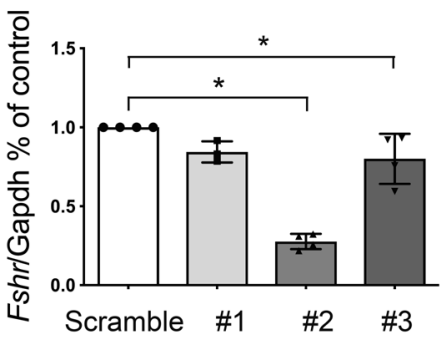

C

FSH

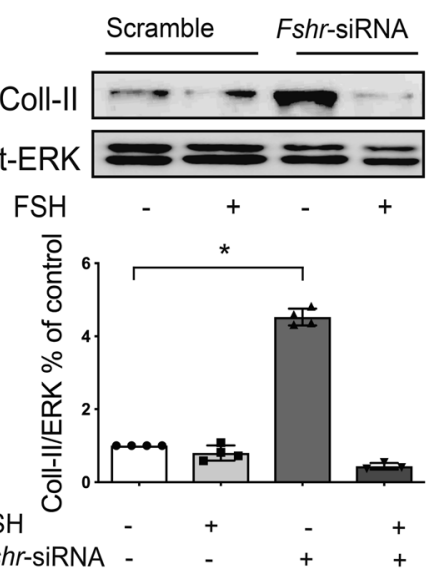

B

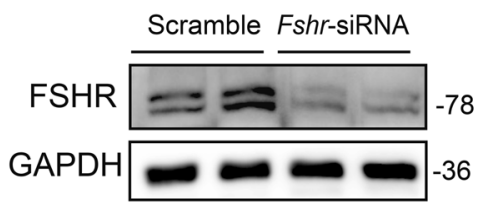

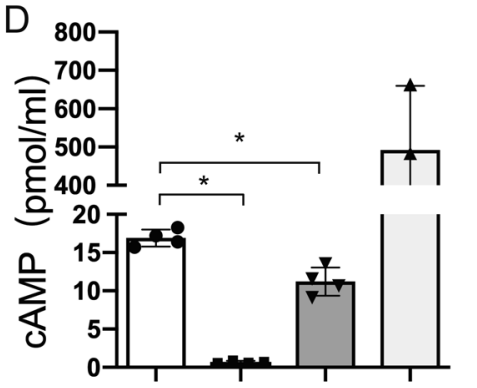

$\begin{array}{lccccc}\text { FSH } & 0 & 30 & 30 & 0 & \mathrm{ng} / \mathrm{ml} \\ \text { PTX } & 0 & 0 & 100 & 0 & \mathrm{ng} / \mathrm{ml} \\ \text { Forsk } & 0 & 0 & 0 & 1 & \mu \mathrm{M}\end{array}$

Figure 3

FSH inhibits Coll-II by binding to FSHR in primary chondrocytes. (A) The efficiency of three pairs Fshr siRNAs $(\# 1, \# 2, \# 3)$ were detected by qRT-PCR. Gapdh was used as a control. $* P<0.05$ vs control. (B) The expression of FSHR after Fshr siRNAs (\#2) interfering was detected by Western blot. (C) Western blot analysis of FSHR in the FSHmediated Coll-II. The effect of FSHR knockdown on the activating effects induced by FSH $(5 \mathrm{ng} / \mathrm{mL})$ was assessed with Fshr-siRNA transfection (100 $n M)$. Western blotting analysis was quantified by Imagej software, $* P<0.05$ vs control. (D) Cyclin AMP (CAMP) analysis of primary chondrocytes in the presence of FSH, PTX (100 ng/mL), Forsk was used as a positive control. PTX, pertussis toxin; Forsk, forskolin. ( ${ }^{*} P<0.05$ vs control). downregulated Coll-II. The same mechanism was found in a previous study showing that FSHR interacts with Goi and induces osteoclast differentiation (Sun et al. 2006). We also observed a slightly inhibited p-p38 phosphorylation after PTX treatment (Fig. 4D). The same phenomenon was found in previous studies showing that PTX inhibits p38 and increases ERK-1/2 in chondrocytes (Kim et al. 2005, Xie et al. 2018).

\section{Blocking FSH prevents chondrocyte loss and superficial zone destruction}

Chondrocytes exhibit ranged phenotypic plasticity and have different functions in the different zones of articular cartilage (Stokes et al. 2002). For example, chondrocytes in the superficial zone (SZ) have a flattened, fibroblast-type appearance and have the capability to secrete lubricin to
A

C

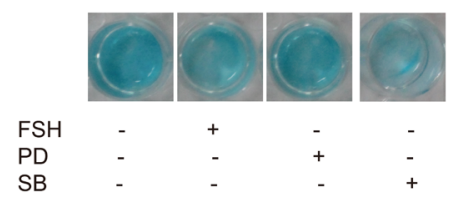

B

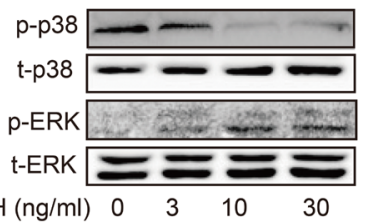

$\begin{array}{lllll}\mathrm{FSH}(\mathrm{ng} / \mathrm{ml}) & 0 & 3 & 10 & 30\end{array}$

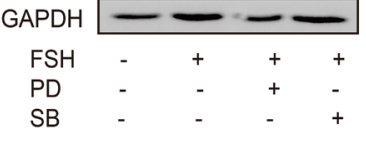

D

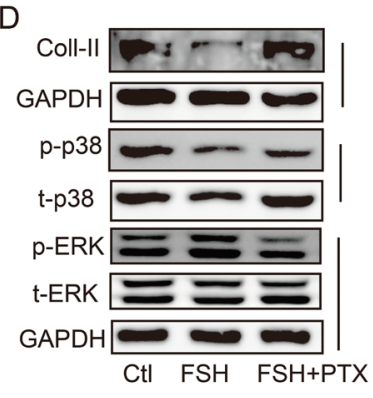

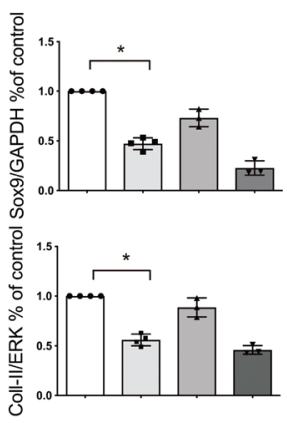

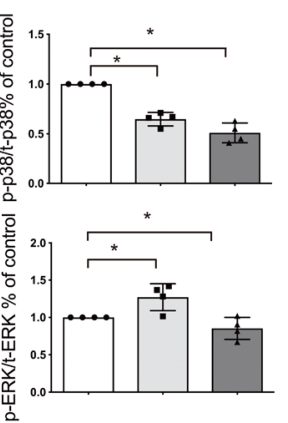

\section{Figure 4}

Effects of FSH on the ERK-1/2 and p38 pathways. (A) FSH dose-dependently induces ERK-1/2 phosphorylation but reduces $\mathrm{p} 38$ phosphorylation in primary chondrocytes. Total ERK-1/2 and total p38 were used as controls. (B) MAPK signaling was inhibited by the ERK-specific inhibitor PD98059 (10 nm) or the p38 inhibitor SB203580 (10 nm) for $30 \mathrm{~min}$ in primary chondrocytes. The cells were then treated with FSH (30 ng/mL) for 30 min in the presence of these inhibitors. Western blotting analysis was quantified by ImageJ software, $* P<0.05$ vs control. (C) ATDC5 cells were cultured in differentiation medium. MAPK signaling was inhibited by the ERK-specific inhibitor PD98059 (10 nm) or the p38 inhibitor SB203580 (10 nm) for $30 \mathrm{~min}$. Then, the cells were treated with 100 $\mathrm{ng} / \mathrm{mL} \mathrm{FSH}$ in the presence of the inhibitors. Alcian blue staining was performed after 3 days. (D) Immunoblotting analysis of FSH (30 ng/mL) with and without PTX (100 ng/mL) on Coll-II, ERK-1/2 and $\mathrm{p} 38$ signaling in ATDC5 cells ( $* P<0.05$ vs controls). 
alleviate the friction of joints (Neu et al. 2007). Spherical chondrocytes in the deep zone can express abundant type X collagen (Coll-X) and are involved in osteogenesis (Sophia Fox et al. 2009). To better illustrate the roles of FSH in cartilage, it is necessary to identify the location of FSHR on cartilage. Our previous study demonstrated that FSHR is located on human and mouse primary chondrocytes using immunoblotting and immunofluorescence (Kong et al. 2018). Here, we found that FSHR is mainly located on the superficial layer of articular cartilage and infrequently in calcified chondrocytes (Fig. 5A). The expression of FSHR strongly implicates a potential role of FSHR signaling in the SZ of healthy and diseased articular cartilage.

Then, we used a polyclonal antibody against FSH $\beta$ to block FSH in mice to study the effects of FSH absence. Previous studies demonstrated that blocking FSH efficiently decreases cholesterol (Guo et al. 2019) and bone loss (Zhu et al. 2012) in mice. Thus, blocking FSH with a FSH antibody in mice is an efficient approach to study the effects of FSH absence. There were no differences in bone length between the two groups (Fig. 5B). Compared with IgG mice, FSHAb mice had significantly increased
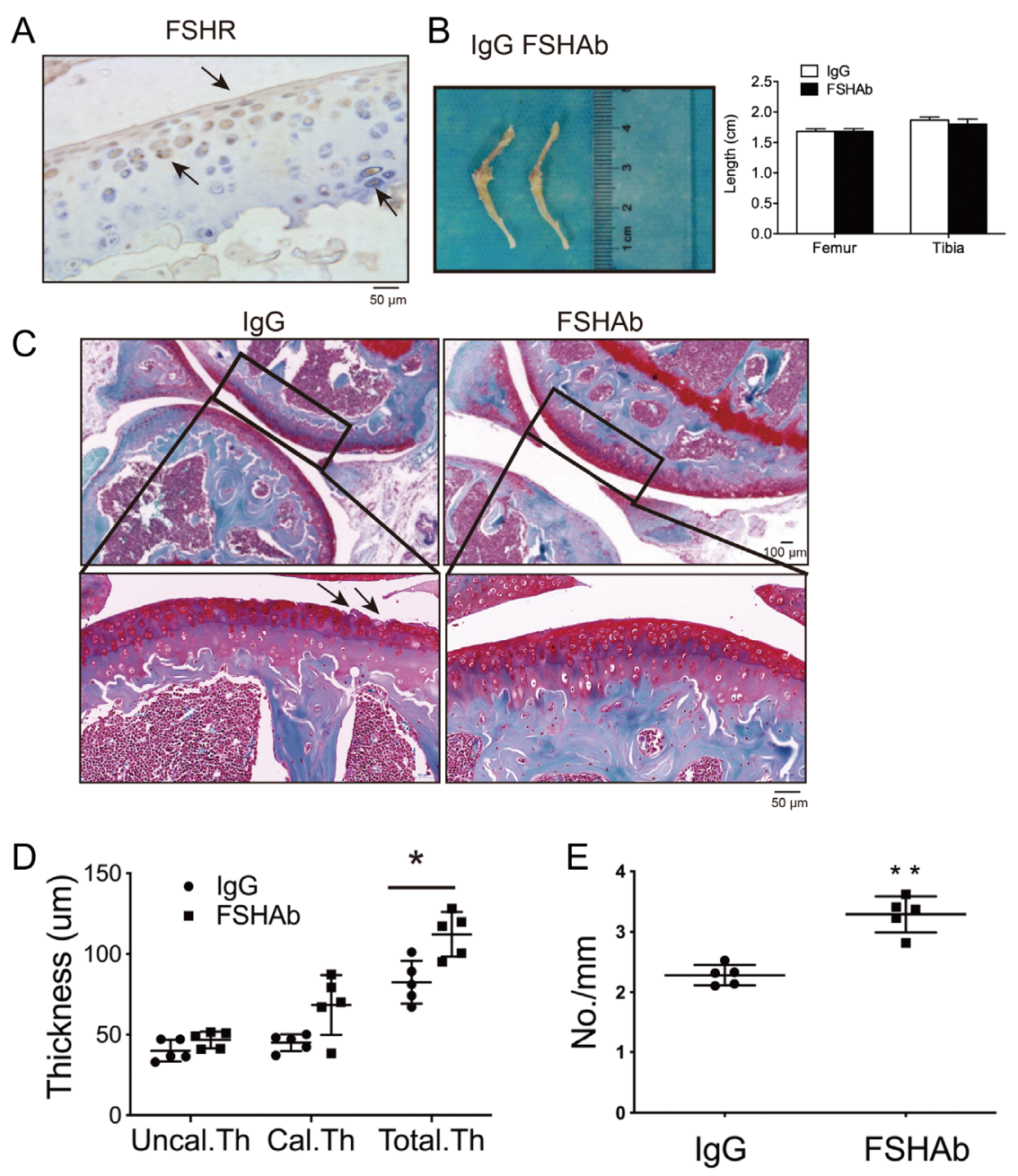

$\mathrm{F}$

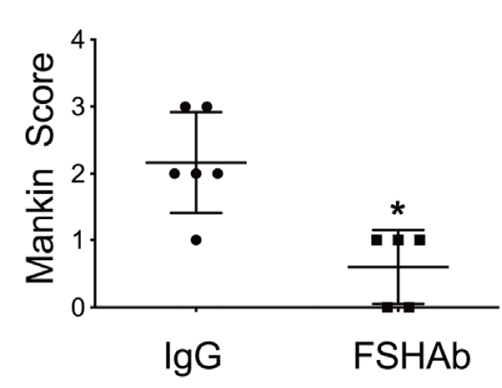

G

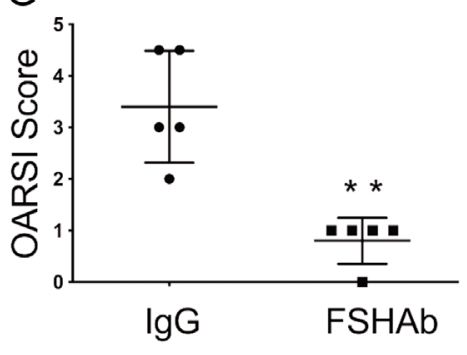

Figure 5

Blocking FSH prevents chondrocyte loss and superficial zone destruction. Mice were injected with FSH antibody or mouse IgG (100 $\mu \mathrm{g} /$ day) for 8 weeks. (A) Immunostaining of FSHR in mouse knee cartilage. Sections were counterstained with toluidine blue to verify proteoglycans. A light microscope was obtained from Leica (DMI 400B, Germany). Scale bars $=50 \mu \mathrm{m}$. (B) Imaging and quantification of femur and tibia length were performed for two groups. (C) Histological images of articular cartilage stained with Safranin O (red) and Fast Green. (D) The thickness of different cartilage zones in the medial tibial plateau of knee cartilage was quantified ( $* P<0.05$ vs IgG mice). Uncal.Th, uncalcified thickness. Cal.Th, Calcified thickness. Total.Th, Total thickness. (E) The number of chondrocytes in the uncalcified zone was quantified ( $* \star P<0.01 \mathrm{vs} \lg \mathrm{G})$. (F) Mankin score shows that mice in the FSHAb group had an improved cartilage phenotype compared with those in the IgG group $(* P<0.05$ vs IgG mice). (G) OARSI score shows that mice in the FSHAb group had an improved cartilage phenotype compared with those in the IgG group (** $P<0.01$ vs IgG mice). 
total cartilage thickness (Fig. 5C and D). Besides, the increased cartilage thickness was also observed in both the uncalcified and calcified zones. Decreased chondrocyte cell numbers (Fig. 5E) and destroyed cartilage (Fig. 5C, see black arrow) were noticeable in the cartilage in IgG mice. While blocking FSH can prevent chondrocyte loss and maintain an intact cartilage surface in FSHAb mice. Moreover, FSHAb mice had enhanced Safranin O staining, decreased Mankin score (Fig. 5F) and OARSI score (Fig. 5G) compared with IgG mice. Thus, blocking FSH in knee cartilage may provide therapeutic strategies for postmenopausal osteoarthritis.

\section{Blocking FSH increases Ki67 and decreases Egr1 staining in cartilage}

Then, we stained Coll-II to explore whether blocking FSH can affect cartilage ECM composition. Results showed that the staining of Coll-II was markedly enhanced in FSHAb mice compared with IgG mice. Moreover, compared with IgG mice, FSHAb mice had increased Ki67 staining, suggesting that FSH signaling may be harmful in chondrocyte survival and proliferation.

To explore whether FSH plays roles in the onset or progression of $\mathrm{OA}$, we analyzed two OA markers, proteoglycan 4 (Prg4, also known as lubricin) and early growth response 1 (Egr1). Prg4 is secreted by SZ chondrocytes and is crucial for reducing the friction of cartilage, while Egr1 has been shown to promote cartilage degeneration and OA onset. By using qRT-PCR, we showed that FSH inhibits Prg4 but increases Egr1 expression in chondrocytes (Fig. 6B). Egr1 expression was further analyzed by using immunofluorescence in ATDC5 cells; results showed an increased staining after FSH treatment (Fig. 6C). However, blocking FSH decreased Egr1 staining in FSHAb mice (Fig. 6D).

A
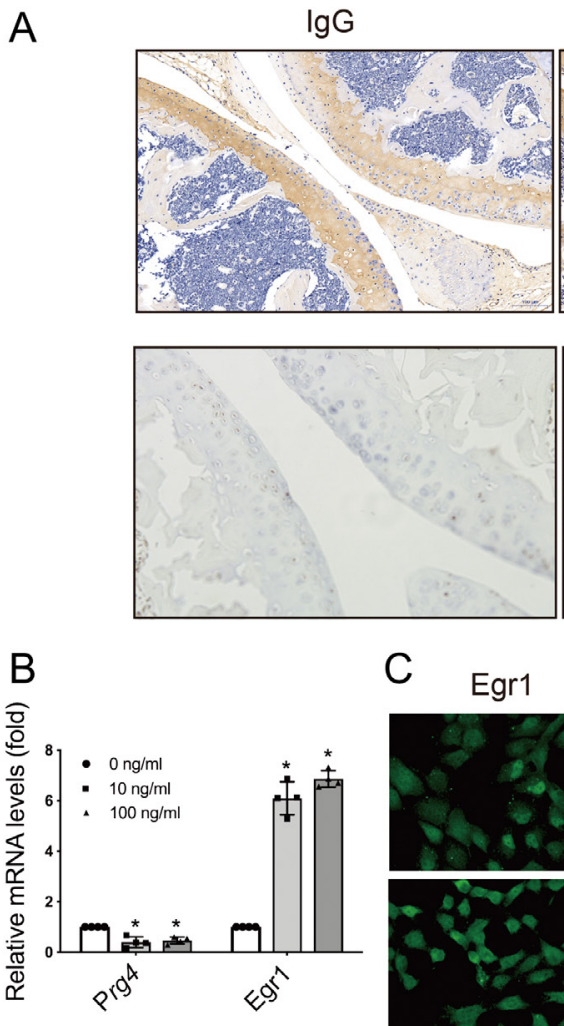

C Egr1

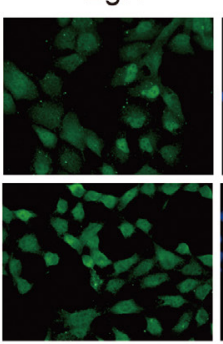

D

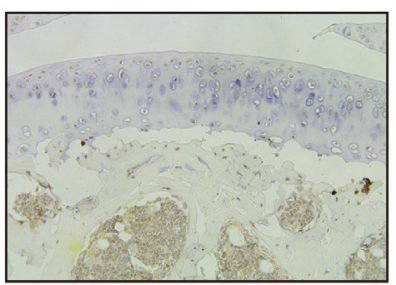

$\lg G$

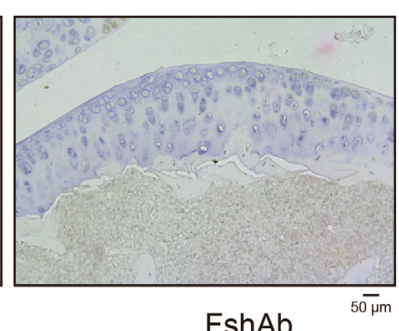

FshAb
FshAb
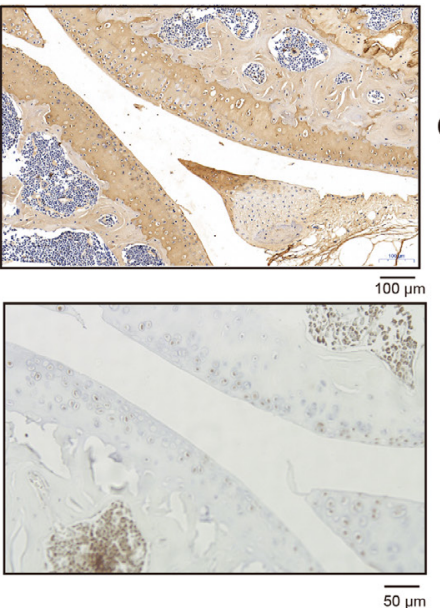

Ki67

Coll-II

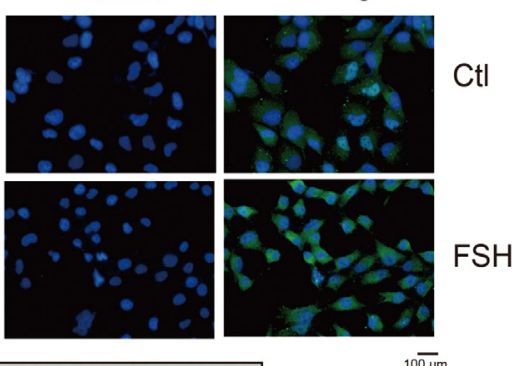

Egr1

(C) 2021 Society for Endocrinology Published by Bioscientifica Ltd.
Printed in Great Britain

\section{Figure 6}

Blocking FSH increases Ki67 but decreases Egr1 staining. (A) Histological images of articular cartilage stained with Coll-II and Ki67. (B) qRT-PCR analysis of Prg4 and Egr1 in primary chondrocytes. Gapdh was used as a control ( $* P<0.05$ vs control). (C) Egr1 expression after FSH (30 ng/mL) treatment for 30 min was analyzed by immunofluorescence in ATDC5 cells. The cell nucleus was labeled with DAPI (blue). Darkfield microscope was obtained from Zeiss (Axio Image A2). Scale bars $=100 \mu \mathrm{m}$. (D) Histological images of articular cartilage stained with Egr1, scale bars $=50 \mu \mathrm{m}$. 
These data suggest that FSH may be a negative regulator in the onset or progression of OA.

\section{Discussion}

The effects of FSH on postmenopausal osteoporosis have been extensively studied by several groups, including our own (Sun et al. 2006, Wang et al. 2015). Whether FSH contributes to cartilage destruction, thus promoting the onset of osteoarthritis, remains unclear. Our previous study has shown that FSHR is located on human and mouse chondrocytes (Kong et al. 2018). However, the underlying mechanisms of FSHR on chondrocytes remain to be elucidated.

During the progression of OA, chondrocytes exhibit multiple pathologic behaviors, such as altered proliferation and cell death; unbalanced synthesis and degradation; changed phenotype and formation of osteophytes (Sandell \& Aigner 2001). Traditionally, the terminal hypertrophic differentiation is considered as one of the key pathologic phenotypes in OA (Dreier 2010, Ripmeester et al. 2018). During which period, chondrocytes start to expresses Coll-X. Meanwhile, chondrocytes express enhanced degradation enzymes, such as MMP13 and MMP3, stimulating Coll-II degradation and subsequently cartilage catabolism (van der Kraan \& van den Berg 2012). However, recent study suggests that inflammatory factors, such as IL-1 and TNF- $\alpha$ can promote chondrocytes into a fibroblast phenotype, a phenotype of dedifferentiation (Murakami et al. 2000, Speichert et al. 2019) And it is increasingly believed that the chondrocyte 'dedifferentiated-like' phenotype also contributes to OA progression (Stokes et al. 2002, Charlier et al. 2019, Ji et al. 2019). Compared to differentiated conditions, dedifferentiated OA chondrocytes can secrete vascular endothelial growth factor (VEGF) in response to proinflammatory factors (Honorati et al. 2004), which may subsequently involve in the vasculogenesis in the progression of OA.

Chondrocyte hypertrophic differentiation and dedifferentiation share some characteristics, such as decreased Coll-II and aggrecan. However, the behavior of the two chondrocyte functions occur via two different mechanisms. Recent study suggests that dedifferentiated chondrocytes start to express some mesenchymal stem cell (MSC) markers (CD49, CD90) (Vinod et al. 2020). Besides, chondrocytes reorganize their actin cytoskeleton and change their morphology to a fibroblast phenotype (Yu et al. 2016b). Much of this was related to the increase of F-actin, which then increased cell stiffness upon dedifferentiation (Sliogeryte et al. 2016). Our results showed that FSH activation shifted the phenotype of ATDC5 cells from a round morphology to a fibroblastic morphology (Fig. 2B), suggesting a trend toward dedifferentiation. Meanwhile, Coll-II was decreased by FSH treatment (Fig. 1C). Therefore, our results suggest that FSH induces dedifferentiation in chondrocytes, which has been suggested to be an early sign of OA onset (Charlier et al. 2019).

Next, we investigated the relationship between Coll-II and its transcription factor SOX9 in FSH-induced dedifferentiation. We detected a decrease in phosphoCREB in our study (Fig. 1C), which was consistent with the decreases in SOX9 and Coll-II. These data suggest that the FSH-mediated downregulation of Coll-II is likely to be regulated by the SOX9/CREB-dependent pathway, which is consistent with a former study (Tsuda et al. 2003).

Previous reports suggest that MAPK signaling is involved in chondrocyte dedifferentiation (Kim et al. 2002, Yu et al. 2016a). In this study, opposite changes in ERK-1/2 (increase) and p38 kinase (decrease) were observed after FSH treatment, the mechanisms of which are similar to the effect of the proinflammatory cytokine IL-1b (Kim et al. 2002). In addition, the FSHmediated inhibition Coll-II could be rescued by the ERK inhibitor PD98059, suggesting that ERK-1/2 activation is involved in FSH-induced dedifferentiation. However, the FSH-mediated inhibition of Coll-II was aggravated by the p38 inhibitor SB203580, suggesting that FSH may exert its effect by inhibiting p38 kinase. In our study, we observed that SOX9 and phospho-p38 were both decreased after FSH treatment. The interactions of P38 MAPK and SOX9 in chondrocyte differentiation have been investigated by Zhang et al., who showed that SOX9 is downstream of p38 MAPK (Zhang et al. 2006). However, further studies need to be employed to discover the interactions of ERK-1/2 and SOX9 in FSHinduced dedifferentiation.

FSH exerts its roles by binding to its receptor FSHR, a member of GPCR family. FSHR can couple to multiple $G$ proteins in a tissue-specific manner. For example, FSH couples with Gos and elevates cAMP in ovarian cells (Conti 2002), while it couples with Goi and inhibits cAMP in osteoclasts (Sun et al. 2006). In the present study, we found that FSH inhibits cAMP production. To identify the underlying mechanism, we introduced a Goi inhibitor (PTX) and found that the inhibition of Goi restored the FSH-mediated decrease in cAMP. Moreover, the FSHinduced decrease in Coll-II was also rescued by PTX, 
implicating a role of the Goi pathway in FSH-induced dedifferentiation. Thus, our results suggest that FSHR may regulate chondrocyte dedifferentiation by interacting with Goi.

The FSH antibody approach has been adopted for studying osteoporosis and adipogenesis after menopause (Zhu et al. 2012, Liu et al. 2017, Guo et al. 2019) and is regarded as a well-characterized method to study FSH absence. Interestingly, blocking FSH increases Coll-II staining in the cartilage, suggesting an inhibition of dedifferentiation. And the in vivo results indicate that blocking FSH prevents chondrocyte loss and increases Ki67 staining in the cartilage, suggesting blocking FSH may be helpful for cell proliferation. Since we did not observe obvious effect of FSH on chondrocyte proliferation in CCK-8 assay. The possible explanation may be that the $72 \mathrm{~h}$ in our in vitro CCK- 8 assay is not sufficient to observe the effect of FSH on cell proliferation since primary chondrocytes have a very slow proliferation rate (Farnum \& Wilsman 1993). Thus, the in vivo results suggest that blocking FSH is a useful tool to promote chondrocyte survival and to resolve the serious problem of dedifferentiation.

Notably, we found that FSH affects OA markers, such as Prg4 and Egr1 (Fig. 6B). The SZ is responsible for producing superficial zone protein (also called Prg4 or lubricin) to reduce the friction of articular cartilage (Poole 1997). Downregulated expression of Prg4 has been observed in early $\mathrm{OA}$ in animal osteoarthritis models (Flannery et al. 2009, Coles et al. 2010), while overexpression of $\operatorname{Prg} 4$ protects against OA (Ruan et al. 2013). Thus, Prg4 acts as a marker of early OA. Moreover, a previous study suggested that $\operatorname{Prg} 4$ is a CREB-dependent gene in articular cartilage (Ogawa et al. 2014). As shown in our results, decreases in Prg4 (Fig. 6B) and phospho-CREB (Fig. 1C) were observed after FSH treatment. Thus, FSH may have roles in the onset of OA by reducing lubricin secretion and increasing the friction of cartilage. Previous study showed that Egr1 promotes cartilage degeneration, chondrocyte hypertrophy, and inhibits extracellular matrix gene expression in chondrocytes (Sun et al. 2019). In addition, Egr1 suppresses col2a1 promoter activity (Tan et al. 2003) and is increased in OA cartilage (Feng \& Lian 2015, Zhang et al. 2016). In our present study, Egr1 transcription was sharply increased after FSH treatment (Fig. 6B). However, Egr1 staining was decreased after blocking FSH (Fig. 6D). Based on published studies, FSHenhanced Egr1 might be regulated by upregulated ERK-1/2 since ERK-1/2 acts upstream of Egr1 (Rockel et al. 2009, Shan et al. 2019).

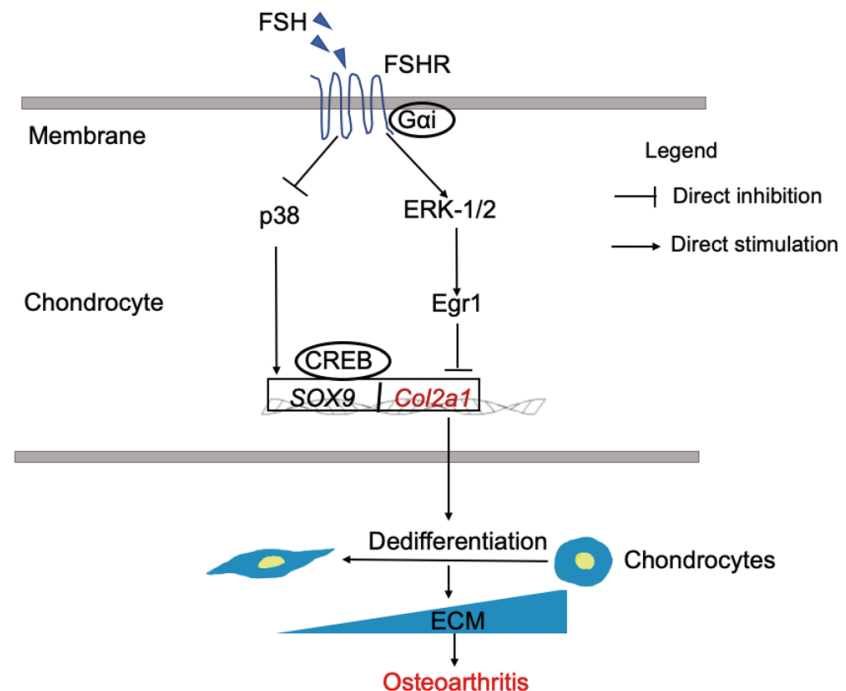

Figure 7

Schematic diagram depicting mechanisms of FSH on chondrocyte dedifferentiation and osteoarthritis. FSH exerts roles by binding to its $\mathrm{G \alpha i}$ coupled FSHR, which then inhibits p38 and activates ERK-1/2 phosphorylation in chondrocytes. The activated ERK-1/2 signaling increases Egr1 accumulation, which then reduces the Col2a1 synthesis. The inhibited p38 signaling decreases SOX9 transcription, the transcription factor of Col2a1. Besides, FSH also decreases the phosphorylation of CREB. As a result, FSH activation leads to decreased Col2a1 transcription and chondrocyte dedifferentiation. Upon dedifferentiation, chondrocytes reorganize their actin cytoskeleton and change their morphology to a fibroblast phenotype. In summary, FSH activation leads to decreased extracellular matrix (ECM) synthesis and chondrocyte dedifferentiation which may exert roles on osteoarthritis (OA).

There are some limitations in our present study. We did not investigate the direct interactions of Goi and MAPK signaling since many studies have shown that MAPK signaling is downstream of Gai (Sun et al. 2006, Goldsmith \& Dhanasekaran 2007, Leroy et al. 2007). Another limitation is that we cannot exclude whether FSH has roles in other cells, such as osteoclasts, that affect the impact of FSH on cartilage. Future considerations of a cartilage-specific knockout animal model could be used to assess the direct relationship between FSH and knee OA.

In conclusion, our present study (summarized in Fig. 7) suggests that FSH acts as a negative regulator in chondrocyte differentiation through the suppression of Coll-II. Plausible mechanisms may be that FSH oppositely regulates ERK-1/2 and p38 kinase. In summary, our study may provide insights into therapeutic options in cartilage disorders, such as postmenopausal osteoarthritis.

\section{Declaration of interest}

The authors declare that there is no conflict of interest that could be perceived as prejudicing the impartiality of the research reported. 


\section{Funding}

This work was supported by the Key Research and Development Plan Project of Shandong Province (grants no. 2016GSF201025, 2016GGH3118, 2017G006006), the National Natural Science Foundation of China (grant no. 81370892), and the Shandong Taishan Scholars Specially invited Expert Plan and Taian Science and Technology Development Plan (grant no. 2018NS0127)

\section{Author contribution statement}

$Y \mathrm{~W}$ and $\mathrm{J} X$ designed the research. $\mathrm{M} \mathrm{Q} \mathrm{Z} \mathrm{Z}$ and $\mathrm{Z} \mathrm{K} \mathrm{H}$ conducted the animal experiments. $Y W, X J Z$ and S S S performed WB, qRT-PCR and IHC. $Y W$ and D H K analyzed the data. Y W and J X wrote the paper.

\section{Acknowledgements}

The authors thank all the support from the colleagues at the Shandong Provincial Key Laboratory of Endocrinology and Lipid Metabolism, Shandong Province, China.

\section{References}

Aigner T, Cook JL, Gerwin N, Glasson SS, Laverty S, Little CB, McIlwraith W \& Kraus VB 2010 Histopathology atlas of animal model systems - overview of guiding principles. Osteoarthritis and Cartilage 18 (Supplement 3) S2-S6. (https://doi.org/10.1016/j.joca.2010.07.013)

Charlier E, Deroyer C, Ciregia F, Malaise O, Neuville S, Plener Z, Malaise M \& de Seny D 2019 Chondrocyte dedifferentiation and osteoarthritis (OA). Biochemical Pharmacology 165 49-65. (https://doi. org/10.1016/j.bcp.2019.02.036)

Coles JM, Zhang L, Blum JJ, Warman ML, Jay GD, Guilak F \& Zauscher S 2010 Loss of cartilage structure, stiffness, and frictional properties in mice lacking PRG4. Arthritis and Rheumatism 62 1666-1674. (https:// doi.org/10.1002/art.27436)

Conti M 2002 Specificity of the cyclic adenosine $3^{\prime}, 5^{\prime}$-monophosphate signal in granulosa cell function. Biology of Reproduction $\mathbf{6 7}$ 1653-1661. (https://doi.org/10.1095/biolreprod.102.004952)

Cui H, Zhao G, Liu R, Zheng M, Chen J \& Wen J 2012 FSH stimulates lipid biosynthesis in chicken adipose tissue by upregulating the expression of its receptor FSHR. Journal of Lipid Research 53 909-917. (https://doi.org/10.1194/jlr.M025403)

Dreier R 2010 Hypertrophic differentiation of chondrocytes in osteoarthritis: the developmental aspect of degenerative joint disorders. Arthritis Research and Therapy 12 216. (https://doi. org/10.1186/ar3117)

Duan L, Liang Y, Ma B, Wang D, Liu W, Huang J, Xiong J, Peng L, Chen J, Zhu W, et al. 2017 DNA methylation profiling in chondrocyte dedifferentiation in vitro. Journal of Cellular Physiology 232 1708-1716. (https://doi.org/10.1002/jcp.25486)

Farnum CE \& Wilsman NJ 1993 Determination of proliferative characteristics of growth plate chondrocytes by labeling with bromodeoxyuridine. Calcified Tissue International 52 110-119. (https://doi.org/10.1007/BF00308319)

Feng Z \& Lian KJ 2015 Identification of genes and pathways associated with osteoarthritis by bioinformatics analyses. European Review for Medical and Pharmacological Sciences 19 736-744.

Flannery CR, Zollner R, Corcoran C, Jones AR, Root A, RiveraBermudez MA, Blanchet T, Gleghorn JP, Bonassar LJ, Bendele AM, et al. 2009 Prevention of cartilage degeneration in a rat model of osteoarthritis by intraarticular treatment with recombinant lubricin.
Arthritis and Rheumatism 60 840-847. (https://doi.org/10.1002/ art.24304)

Goldsmith ZG \& Dhanasekaran DN 2007 G protein regulation of MAPK networks. Oncogene 26 3122-3142. (https://doi.org/10.1038/ sj.onc.1210407)

Gosset M, Berenbaum F, Thirion S \& Jacques C 2008 Primary culture and phenotyping of murine chondrocytes. Nature Protocols 3 1253-1260. (https://doi.org/10.1038/nprot.2008.95)

Guo Y, Zhao M, Bo T, Ma S, Yuan Z, Chen W, He Z, Hou X, Liu J, Zhang Z, et al. 2019 Blocking FSH inhibits hepatic cholesterol biosynthesis and reduces serum cholesterol. Cell Research 29 151-166. (https://doi. org/10.1038/s41422-018-0123-6)

Honorati MC, Cattini L \& Facchini A 2004 IL-17, IL-1 $\beta$ and TNF- $\alpha$ stimulate VEGF production by dedifferentiated chondrocytes. Osteoarthritis and Cartilage 12 683-691. (https://doi.org/10.1016/j. joca.2004.05.009)

Hunter DJ \& Bierma-Zeinstra S 2019 Osteoarthritis. Lancet 393 1745-1759. (https://doi.org/10.1016/S0140-6736(19)30417-9)

Ji Q, Zheng Y, Zhang G, Hu Y, Fan X, Hou Y, Wen L, Li L, Xu Y, Wang Y, et al. 2019 Single-cell RNA-seq analysis reveals the progression of human osteoarthritis. Annals of the Rheumatic Diseases 78 100-110. (https://doi.org/10.1136/annrheumdis-2017-212863)

Johnson K, Zhu S, Tremblay MS, Payette JN, Wang J, Bouchez LC, Meeusen S, Althage A, Cho CY, Wu X, et al. 2012 A stem cell-based approach to cartilage repair. Science 336 717-721. (https://doi. org/10.1126/science.1215157)

Kim SJ, Ju JW, Oh CD, Yoon YM, Song WK, Kim JH, Yoo YJ, Bang OS, Kang SS \& Chun JS 2002 ERK-1/2 and p38 kinase oppositely regulate nitric oxide-induced apoptosis of chondrocytes in association with p53, caspase-3, and differentiation status. Journal of Biological Chemistry 277 1332-1339. (https://doi.org/10.1074/jbc.M107231200)

Kim MK, Lee HY, Park KS, Shin EH, Jo SH, Yun J, Lee SW, Yoo YH, Lee YS, Baek SH, et al. 2005 Lysophosphatidic acid stimulates cell proliferation in rat chondrocytes. Biochemical Pharmacology 70 1764-1771. (https://doi.org/10.1016/j.bcp.2005.09.015)

Kobayashi T, Chung UI, Schipani E, Starbuck M, Karsenty G, Katagiri T, Goad DL, Lanske B \& Kronenberg HM 2002 PTHrP and Indian hedgehog control differentiation of growth plate chondrocytes at multiple steps. Development 129 2977-2986.

Kong D, Guan Q, Li G, Xin W, Qi X, Guo Y, Zhao J, Xu J, Sun S \& Gao L 2018 Expression of FSHR in chondrocytes and the effect of FSH on chondrocytes. Biochemical and Biophysical Research Communications 495 587-593. (https://doi.org/10.1016/j.bbrc.2017.11.053)

Leroy D, Missotten M, Waltzinger C, Martin T \& Scheer A 2007 G protein-coupled receptor-mediated ERK1/2 phosphorylation: towards a generic sensor of GPCR activation. Journal of Receptor and Signal Transduction Research 27 83-97. (https://doi. org/10.1080/10799890601112244)

Li M, Zhao J \& Jia L 2019a USP14-mediated IкB $\alpha$ degradation exacerbates NF-kB activation and IL-1 $\beta$-stimulated chondrocyte dedifferentiation. Life Sciences 218 147-152. (https://doi.org/10.1016/j.lfs.2018.12.014)

Li Z, Liu T, Gilmore A, Gomez NM, Fu C, Lim J, Yang S, Mitchell CH, Li YP, Oursler MJ, et al. 2019b Regulator of G protein signaling Protein 12 (Rgs12) controls mouse osteoblast differentiation via calcium channel/oscillation and Galphai-ERK signaling. Journal of Bone and Mineral Research 34 752-764. (https://doi.org/10.1002/jbmr.3645)

Liu XM, Chan HC, Ding GL, Cai J, Song Y, Wang TT, Zhang D, Chen H, Yu MK, Wu YT, et al. 2015 FSH regulates fat accumulation and redistribution in aging through the Galphai/Ca(2+)/CREB pathway. Aging Cell 14 409-420. (https://doi.org/10.1111/acel.12331)

Liu P, Ji Y, Yuen T, Rendina-Ruedy E, DeMambro VE, Dhawan S, AbuAmer W, Izadmehr S, Zhou B, Shin AC, et al. 2017 Blocking FSH induces thermogenic adipose tissue and reduces body fat. Nature $\mathbf{5 4 6}$ 107-112. (https://doi.org/10.1038/nature22342)

Ma B, Leijten JC, Wu L, Kip M, van Blitterswijk CA, Post JN \& Karperien M 2013 Gene expression profiling of dedifferentiated https://joe.bioscientifica.com

https://doi.org/10.1530/JOE-20-0390 (c) 2021 Society for Endocrinology Published by Bioscientifica Ltd. Printed in Great Britain 
human articular chondrocytes in monolayer culture. Osteoarthritis and Cartilage 21 599-603. (https://doi.org/10.1016/j.joca.2013.01.014)

Mankin HJ, Dorfman H, Lippiello L \& Zarins A 1971 Biochemical and metabolic abnormalities in articular cartilage from osteo-arthritic human hips. II. Correlation of morphology with biochemical and metabolic data. Journal of Bone and Joint Surgery: American Volume 53 523-537. (https://doi.org/10.2106/00004623-197153030-00009)

Martin-Millan M \& Castaneda S 2013 Estrogens, osteoarthritis and inflammation. Joint Bone Spine 80 368-373. (https://doi.org/10.1016/j. jbspin.2012.11.008)

Murakami S, Lefebvre V \& de Crombrugghe B 2000 Potent inhibition of the master chondrogenic factor Sox9 gene by interleukin-1 and tumor necrosis factor-alpha. Journal of Biological Chemistry 275 3687-3692. (https://doi.org/10.1074/jbc.275.5.3687)

Neu CP, Khalafi A, Komvopoulos K, Schmid TM \& Reddi AH 2007 Mechanotransduction of bovine articular cartilage superficial zone protein by transforming growth factor beta signaling. Arthritis and Rheumatism 56 3706-3714. (https://doi.org/10.1002/art.23024)

Ogawa H, Kozhemyakina E, Hung HH, Grodzinsky AJ \& Lassar AB 2014 Mechanical motion promotes expression of Prg4 in articular cartilage via multiple CREB-dependent, fluid flow shear stress-induced signaling pathways. Genes and Development 28 127-139. (https://doi. org/10.1101/gad.231969.113)

Poole CA 1997 Articular cartilage chondrons: form, function and failure. Journal of Anatomy 191 1-13. (https://doi.org/10.1046/j.14697580.1997.19110001.x)

Pritzker KP, Gay S, Jimenez SA, Ostergaard K, Pelletier JP, Revell PA, Salter D \& van den Berg WB 2006 Osteoarthritis cartilage histopathology: grading and staging. Osteoarthritis and Cartilage $\mathbf{1 4}$ 13-29. (https://doi.org/10.1016/j.joca.2005.07.014)

Rim YA, Nam Y \& Ju JH 2020 The role of chondrocyte hypertrophy and senescence in osteoarthritis initiation and progression. International Journal of Molecular Sciences 21 2358. (https://doi.org/10.3390/ ijms21072358)

Ripmeester EGJ, Timur UT, Caron MMJ \& Welting TJM 2018 Recent insights into the contribution of the changing hypertrophic chondrocyte phenotype in the development and progression of osteoarthritis. Frontiers in Bioengineering and Biotechnology 618. (https://doi.org/10.3389/fbioe.2018.00018)

Rockel JS, Bernier SM \& Leask A 2009 Egr-1 inhibits the expression of extracellular matrix genes in chondrocytes by TNFalpha-induced MEK/ERK signalling. Arthritis Research and Therapy 11 R8. (https://doi org/10.1186/ar2595)

Ruan MZ, Erez A, Guse K, Dawson B, Bertin T, Chen Y, Jiang MM, Yustein J, Gannon F \& Lee BH 2013 Proteoglycan 4 expression protects against the development of osteoarthritis. Science Translational Medicine 5 176ra34. (https://doi.org/10.1126/scitranslmed.3005409)

Sandell LJ \& Aigner T 2001 Articular cartilage and changes in arthritis. An introduction: cell biology of osteoarthritis. Arthritis Research $\mathbf{3}$ 107-113. (https://doi.org/10.1186/ar148)

Shan J, Dudenhausen E \& Kilberg MS 2019 Induction of early growth response gene 1 (EGR1) by endoplasmic reticulum stress is mediated by the extracellular regulated kinase (ERK) arm of the MAPK pathways. Biochimica et Biophysica Acta: Molecular Cell Research 1866 371-381. (https://doi.org/10.1016/j.bbamcr.2018.09.009)

Sliogeryte K, Botto L, Lee DA \& Knight MM 2016 Chondrocyte dedifferentiation increases cell stiffness by strengthening membraneactin adhesion. Osteoarthritis and Cartilage 24 912-920. (https://doi. org/10.1016/j.joca.2015.12.007)

Sophia Fox AJ, Bedi A \& Rodeo SA 2009 The basic science of articular cartilage: structure, composition, and function. Sports Health $\mathbf{1}$ 461-468. (https://doi.org/10.1177/1941738109350438)

Speichert S, Molotkov N, El Bagdadi K, Meurer A, Zaucke F \& JeneiLanzl Z 2019 Role of norepinephrine in IL-1 1 -induced chondrocyte dedifferentiation under Physioxia. International Journal of Molecular Sciences 20 1212. (https://doi.org/10.3390/ijms20051212)
Stokes DG, Liu G, Coimbra IB, Piera-Velazquez S, Crowl RM \& Jimenez SA 2002 Assessment of the gene expression profile of differentiated and dedifferentiated human fetal chondrocytes by microarray analysis. Arthritis and Rheumatism 46 404-419. (https://doi.org/10.1002/ art.10106)

Sun L, Peng Y, Sharrow AC, Iqbal J, Zhang Z, Papachristou DJ, Zaidi S, Zhu LL, Yaroslavskiy BB, Zhou H, et al. 2006 FSH directly regulates bone mass. Cell 125 247-260. (https://doi.org/10.1016/j. cell.2006.01.051)

Sun X, Huang H, Pan X, Li S, Xie Z, Ma Y, Hu B, Wang J, Chen Z \& Shi P 2019 EGR1 promotes the cartilage degeneration and hypertrophy by activating the Kruppel-like factor 5 and beta-catenin signaling. Biochimica et Biophysica Acta: Molecular Basis of Disease 1865 2490-2503. (https://doi.org/10.1016/j.bbadis.2019.06.010)

Tan L, Peng H, Osaki M, Choy BK, Auron PE, Sandell LJ \& Goldring MB 2003 Egr-1 mediates transcriptional repression of COL2A1 promoter activity by interleukin-1beta. Journal of Biological Chemistry $\mathbf{2 7 8}$ 17688-17700. (https://doi.org/10.1074/jbc.M301676200)

Tsuda M, Takahashi S, Takahashi Y \& Asahara H 2003 Transcriptional co-activators CREB-binding protein and p300 regulate chondrocytespecific gene expression via association with Sox9. Journal of Biological Chemistry 278 27224-27229. (https://doi.org/10.1074/jbc. M303471200)

van der Kraan PM \& van den Berg WB 2012 Chondrocyte hypertrophy and osteoarthritis: role in initiation and progression of cartilage degeneration? Osteoarthritis and Cartilage 20 223-232. (https://doi. org/10.1016/j.joca.2011.12.003)

Vinod E, Kachroo U, Amirtham SM, Ramasamy B \& Sathishkumar S 2020 Comparative analysis of fresh chondrocytes, cultured chondrocytes and chondroprogenitors derived from human articular cartilage. Acta Histochemica 122 151462. (https://doi.org/10.1016/j. acthis.2019.151462)

Wang J, Zhang W, Yu C, Zhang X, Zhang H, Guan Q, Zhao J \& $\mathrm{Xu} \mathrm{J} 2015$ Follicle-stimulating hormone increases the risk of postmenopausal osteoporosis by stimulating osteoclast differentiation. PLOS ONE 10 e0134986. (https://doi.org/10.1371/ journal.pone.0134986)

Xie Z, Khair M, Shaukat I, Netter P, Mainard D, Barre L \& Ouzzine M 2018 Non-canonical Wnt induces chondrocyte de-differentiation through frizzled 6 and DVL-2/B-raf/CaMKIIalpha/syndecan 4 axis. Cell Death and Differentiation 25 1442-1456. (https://doi.org/10.1038/s41418017-0050-y)

Xin W, Heilig J, Paulsson M \& Zaucke F 2015 Collagen II regulates chondroycte integrin expression profile and differentiation. Connective Tissue Research 56 307-314. (https://doi.org/10.3109/0300 8207.2015.1026965)

Yu SM \& Kim SJ 2015 The thymoquinone-induced production of reactive oxygen species promotes dedifferentiation through the ERK pathway and inflammation through the p38 and PI3K pathways in rabbit articular chondrocytes. International Journal of Molecular Medicine 35 325-332. (https://doi.org/10.3892/ijmm.2014.2014)

Yu SM, Yeo HJ, Choi SY \& Kim SJ 2016a Cytokine-induced apoptosis inhibitor- 1 causes dedifferentiation of rabbit articular chondrocytes via the ERK-1/2 and p38 kinase pathways. International Journal of Biochemistry and Cell Biology 80 10-18. (https://doi.org/10.1016/j. biocel.2016.09.014)

Yu SM, Cho H, Kim GH, Chung KW, Seo SY \& Kim SJ 2016b Berberine induces dedifferentiation by actin cytoskeleton reorganization via phosphoinositide 3-kinase/Akt and p38 kinase pathways in rabbit articular chondrocytes. Experimental Biology and Medicine 241 800-807. (https://doi.org/10.1177/1535370216631028)

Zhang R, Murakami S, Coustry F, Wang Y \& de Crombrugghe B 2006 Constitutive activation of MKK6 in chondrocytes of transgenic mice inhibits proliferation and delays endochondral bone formation. PNAS 103 365-370. (https://doi.org/10.1073/ pnas.0507979103) https://joe.bioscientifica.com

https://doi.org/10.1530/JOE-20-0390 (c) 2021 Society for Endocrinology Published by Bioscientifica Ltd. Printed in Great Britain 
Zhang X, Yuan Z \& Cui S 2016 Identifying candidate genes involved in osteoarthritis through bioinformatics analysis. Clinical and Experimental Rheumatology 34 282-290.

Zhang Y \& Jordan JM 2010 Epidemiology of osteoarthritis. Clinics in Geriatric Medicine 26 355-369. (https://doi.org/10.1016/j.cger.2010.03.001)
Zhu LL, Blair H, Cao J, Yuen T, Latif R, Guo L, Tourkova IL, Li J, Davies TF, Sun L, et al. 2012 Blocking antibody to the beta-subunit of FSH prevents bone loss by inhibiting bone resorption and stimulating bone synthesis. PNAS 109 14574-14579. (https://doi.org/10.1073/ pnas.1212806109)

Received in final form 25 November 2020

Accepted 8 December 2020

Accepted Manuscript published online 9 December 2020 (c) 2021 Society for Endocrinology Published by Bioscientifica Ltd. 